\section{Ophthalmic Research}

\author{
E. Zrenner ${ }^{\mathrm{a}}$ \\ V.-P. Gabel b \\ H. Haemmerle \\ B. Hoefflinger ${ }^{\mathrm{d}}$ \\ M. Schubert \\ a University Eye Hospital, \\ Tübingen, and \\ b University Eye Hospital, \\ Regensburg, \\ c Natural and Medical Science \\ Institute at the University of \\ Tübingen, Reutlingen, \\ Institutes for \\ ${ }^{d}$ Micro-Electronics and \\ e Physical Electronics, Stuttgart, \\ Germany
}

Dear Sir,

Thank you for making us aware of the letter of Dr. Chow from Optobionics Corporation. The issue raised here is the question of proper handling of scientific information.

It is undoubtedly highly unusual that a publication in a respected scientific journal is attacked by a third party in the name of this party's commercial enterprise basing the accusations primarily on commercial and legal aspects. Although we had initially not intended to comment on such argumentations, we now feel that we cannot let the allegations of Dr. Chow stand as they are because in our opinion the allegations clearly have no basis at all.

As we have quoted correctly in our paper [1], Dr. Chow had published one abstract [2] relating to a subretinal implant in 1993. Considering that Dr. Chow has emphasized on his patents, it should be mentioned in this instance that reti-
Ophthalmic Res 1998;30:197-198

\title{
Subretinal Implants
}

nal and subretinal implants as such had been well known in the patent literature long before 1993 (e.g. US patient No. 2,760,483 published in 1956 and US patent No. 4,628,933 published in 1986). The scientific literature long before 1993, too, comprises various publications covering retinal prostheses, e.g. by Kataoka [3] or Melen et al. [4].

In fact, we have never boasted ourselves, either explicitly or implicitly, of having been the first to have had the idea of a subretinal implant. Unfortunately at the time of invited submission of the manuscript to Ophthalmic Research and at the time of galley proof correction, the publication of Chow and Chow [6] had not yet been published, and it was therefore not possible to quote this particular paper. We therefore had to rely on the ARVO abstract quoted [2]. We received a reprint of Dr. Chow's paper [6] with a letter of his co-worker dated October 8, 1997, long after our galley proofs had been sent to Ophthalmic Research.

Dr. Chow has added to his letter a long list of references. We have not quoted patents since this is unusual in a biological journal and since patents are rather a claim of rights to a technical invention (ref. 2-4 in Dr. Chow's letter) being a matter of commercial exploitation that is not necessarily cited in scientific journals. It is also quite unusual that Dr. Chow wants us to quote unpublished applications and unpublished documentation (ref. 9-11). Reference 12 is from a journal not listed in the Science Citation Index (SCI) nor known to us, apparently a report. Reference 13 is an oral presentation which Dr. Peachey gave in our Eye Hospital on electrophysiological recordings in a regular morning seminar.

We do think that we have properly quoted Dr. Chow's work by referring to the ARVO abstract which relates to the development, presented in our paper. His other abstracts which Dr. Chow quotes in his letter (ref. 7 and 8) do not relate to the development of a subretinal microphotodiode but rather concern the effect of intraocular pressure on retinal potentials (which can be induced by many ways, certainly also by a subretinal microphotodiode array) as well as a particular experiment with a microphotodiode array (ref. 8 in Dr. Chow's letter).

It should be obvious to the reader of Dr. Chow's and our letter that at the time of publication of our paper we have done our best to quote properly the relevant work of Dr. Chow, available to the scientific community at that time. It was also very clear that the wide range of topics covered in our article [1] from development to biocompatibility and adhesion problems as

\footnotetext{
KARGER

Fax +41613061234

$\begin{array}{ll}\text { E-Mail karger@karger.ch } & \text { This article is also accessible online at: } \\ \text { www.karger.com } & \text { http://BioMedNet.com/karger }\end{array}$

() 1998 S. Karger AG, Basel

0030-3747/98/0303-01978

http://BioMedNet.com/karger
} 
well as in vitro and vivo measurements - demanded to restrict citations to the absolute necessity, given by the organizer of the meeting from which the particular issue of Ophthalmic Research originated.

It is certainly appropriate in science to base developments on experiences of others, and nobody would consider it an improper act if for instance a recording electrode would have a certain length, a certain diameter and a certain configuration as published by others, when properly quoted. We have in the meantime developed numerous different types of subretinal microphotodiodes and it should be noted that all the production, all the biological experiments which include biocompatibility and adhesion studies as well as in vitro techniques [5] have been developed far beyond what Dr. Chow and associates have reported so far.

Indeed, we had long discussions with Dr. A. Chow at the initial stage of our project when he informed us to the effect that he is a single scientist with no particular institutional background behind him doing much of his scientific work together with various colleagues in the United States. We have grouped together various university and medical school institutes having profound knowledge and experience in the medical aspects as well as in semiconductor technology and having the necessary research facilities. For that purpose we had obtained substantial funding from the German Government. All these facts had been disclosed to Dr. Chow who was invited to join us and for whom a considerable portion of the funds had been set aside. However, Dr. Chow had insisted that he retains all commercial rights in any results emanating from this funded project and his financial demands were exorbitant and completely out of proportion.
Under these circumstances it was simply impossible also for German funding authorities to go on with any cooperation with Dr. Chow, because under the applicable funding provisions any such commercial agreement would have been out of discussion. Our lawyers have, therefore, urgently recommended to terminate the discussions with Dr. Chow. We have, therefore, developed the entire technology by ourselves and without any further input whatsoever from Dr. Chow. We in fact deeply regret that these circumstances which, in the best interest of Dr. Chow, should have remained confidential, must now be disclosed in view of his attacks against us.

We have certainly not violated standard codes of ethics and scientific conduct. We do hope that the scientific community can properly judge about the motives of Optobionics Corporation to write the above mentioned letter.

\section{References}

1 Zrenner E, Miliczek K-D, Gabel VP, Graf HG, Günther E, Hämmerle $\mathrm{H}$, Höfflinger B, Kohler K, Nisch W, Schubert M, Stett A, Weiss S: The development of subretinal microphotodiodes for replacement of degenerated photoreceptors. Ophthalmic Res 1997;29:269280.
2 Chow AY: Electrical stimulation of the rabbit retina with subretinal electrodes and high density microphotodiode array implants. ARVO abstracts. Invest Ophthalmol Vis Sci 1993;34:835.

3 Kataoka S: An attempt towards an artificial retina. Transducers 85 , Int Conf Solid-State Sensors Actuators, Philadelphia, 1985, pp 440-442.

4 Melen RD, Meindl JD: A transparent electrode CCD image sensor for a reading aid for the blind. IEES $\mathrm{J}$ Solid-State Circuits 1974;SC-9:4149.
5 Stett A, Weiss S, Gnauck P, Stelzle M, Nisch W, Haemmerle H, Zrenner E: Towards a subretinal implant: Investigations on the chip/retina interface. Invest Ophthalmol Vis Sci 1997;38:41.

6 Chow AY, Chow VY: Subretinal electrical stimulation of the rabbit retina. Neurosci Lett 1997;225:1316.

Prof. Eberhart Zrenner

University Eye Hospital, Department II, Schleichstrasse 12

D-72076 Tübingen (Germany)

Tel. 7071 2984786, Fax 7071 295038,E-Mail ezrenner@uni-tuebingen.de 